ESJ Humanities

\title{
Integrating English for Academic Writing Virtual Lab Setting in Pre-Service Math and Science Teacher Education Programs
}

\author{
Haggag Mohamed Haggag, PhD \\ Assistant Professor of Curricula and TEFL Methodology \\ South Valley University, Egypt
}

Doi:10.19044/esj.2022.v18n2p1

Submitted: 02 December 2021

Accepted: 20 January 2022

Published: 31 January 2022
Copyright 2022 Author(s)

Under Creative Commons BY-NC-ND

4.0 OPEN ACCESS

Cite As:

Haggag H.M. (2022). Integrating English for Academic Writing Virtual Lab Setting in PreService Math and Science Teacher Education Programs. European Scientific Journal, ESJ, 18 (2), 1. https://doi.org/10.19044/esj.2022.v18n2p1

\section{Abstract}

This research focuses on identifying the effect of integrating English for academic writing virtual lab setting in pre-service math and science teacher education programs. Four instruments were utilized in the different process of the research and the test was reported in the results. It utilized English for academic writing questionnaire to identify the academic writing skills needed for the participants, while a virtual academic writing module was used in the instruction of the target skills. English was utilized for the academic writing test and its rubric was used in the pre-post testing of the participants and their assessment. The participants were pre-service students $(\mathrm{N}=58)$ from math and science departments at Hurghada Faculty of Education, South Valley University, Egypt. Using a one-group quasi-experimental design, the research followed a pre and post testing procedure before and after applying the virtual academic writing lab. Results of the study were obtained quantitatively and qualitatively through the test of academic writing and the reflection sheet, respectively. Quantitative results showed that there were significant mean differences between participants' scores at level $0.05 \geq$ in the pre and post testing procedure. These differences were in favor of the post testing of both basic academic writing concepts' variable and academic writing skills variable (000), as well as the total score of participants' academic writing (sig .002). Qualitative results also showed the positive attitudes of the participants and 
their satisfaction with the online module based on the feedback provided during the writing process. Recommendations of the research included integrating online virtual writing labs in pre-service math and science teachers' education programs as well as integrating academic writing in their academic English courses.

Keywords: Virtual Lab, Academic Writing, Math, Science

\section{Introduction}

In academic settings "environments", writing is a key language skill to develop during pre-service teacher education programs especially in English as a Foreign Language (EFL) context. For instance, Alqiawi (2015) expressed the view that "in the academic situation and especially at the university level, writing possesses extra importance as it is the tool for communication through which students should express their ideas with clarity and ease. At university level, students are supposed to learn to write properly and accurately as they are being prepared to get a job or to complete higher studies and in both situations they need good writing skills" (p. 313). Writing academically is both a university requirement and a career path since this entails expressing thought in a clear and concise way.

Academic writing which is formally structured and supported by evidence type of writing can be defined in different aspect. One aspect defines it as a global educational requirement with distinctive descriptors. Another definition states that academic writing is a type of writing that is "clear, concise, focused, structured, and backed up by evidence. Its purpose is to aid the reader's understanding" (University of Leeds, 2019). Writing academically is a global requirement in most of the world education references. For instance, the Common European Framework of Reference (CEFR) views a proficient user (C2) as one who can understand with ease virtually everything heard or read; can summarize information from different spoken and written sources, and reconstruct arguments and accounts in a coherent presentation. Also, it involves a user who can express himself/herself spontaneously, fluently, and precisely by differentiating finer shades of meaning even in more complex situations (CEFR, 2021). Writing academically is a requirement for different teacher education programs including math and science disciplines.

Literature in academic writing field (Hussein \& El Mahallawi, 2018; Hyland, 2007; Yang \& Allison, 2004) further highlights the need to develop such crucial area for both academic and job needs. For instance, Ali, Qoura, and Al Sheikh (2018) stressed the "publish or perish" and the need to view academic writing as a process rather than a social practice or mere perfect essays for certain purposes. Similarly, academic writing practice has been 
discussed by various studies. The view and the practice of academic writing instruction is categorized into four types: descriptive, analytical, persuasive, and critical writing in both frontal and virtual environments (Abbadi, 2013; Ahmad, 2020; Al Hussein, 2018; Summers, 2019).

Using virtual learning environments that entail online writing centers have been a subject for study in a variety of recent studies that investigated the development of academic writing (Adam \& Tatnall, 2010; Ahmed, 2002; Mohamed, 2019; Alqiawi, 2015). Virtual writing labs are one of the writing environments which utilizes technology and internet-based environments in the instruction of writing. Writing labs in university education (Mackiewicz \& Thompson, 2018) have developed from writing a range of essays, capstones, thesis and dissertations, to "evolving from an overriding concern with pedagogical triage to concern for helping student writers enter the disciplinary conversations that they encounter during their academic careers" (p.48). More so, roles of writing centers have developed from mere writing practice to virtual academic discussions.

The Egyptian teacher education policy has greatly developed since 2018 through a national reform project with the aid of World Bank (Ewiss, 2020). This reform highlighted the use of online learning and online projects in both student instruction and teacher education projects. Furthermore, the national approach has been greatly strengthened during this COVID-19 period. Its goals are "to hire new teachers and school leaders, provide digital skills training, improve the electronic technical support including iPad and laptops, and develop a reliable and fair electronic assessment methods" (p.46). In this national vision, there is a need to provide authentic and comprehensive virtual environments or settings in teacher education for different specializations including math and science as well. Therefore, the present research seeks to integrate English for academic writing virtual lab setting in pre-service math and science teacher education program in South Valley University, Egypt.

\section{Problem of the Research}

Based on literature review (Abdrabo, 2020; Ali, Qoura, \& Al Sheikh, 2018; Alqiawi, 2015; Yang \& Allison, 2004; Mohamed, 2019; Tan, 2020; Webb, 2021), it is evident that using online writing labs in pre-service teacher education may enhance their language and professional performance as well. Similarly, based on the researcher's experience in teaching English, math, and science for university students and based on exam results of the students, the problem of the study emerges. It identifies that some pre-service math and science teachers lack many academic English writing skills including identifying writing concepts, writing process, editing, and publishing. Thus, 
there is a need to design and implement an online environment to develop their academic writing skills.

\section{Objectives of the Research}

The research aims to achieve the following:

3.1. Compiling and setting an academic English virtual writing lab for preservice math and science teachers.

3.2. Identifying the effect of the writing lab on participants' basic academic writing concepts (e.g., models of writing, elements of writing and stages of writing).

3.3. Identifying the effect of the writing lab on participants' academic writing skills (e.g., prewriting- paragraph writing - editing publishing).

\section{Significance of the Research}

The research is thought to be significant for the following reasons outlined below:

4.1. Identifying English for academic writing skills that are needed for pre-service math and science teachers, which are essential for research and course designers.

4.2. Designing English academic writing virtual lab for pre-service math and science teachers. This could be helpful for their professional development and academic achievement.

4.3. For course designers, the research compiles a writing lab and online materials that can be part of academic writing courses.

4.4. Teachers at both pre and in service levels can make use of the instruments and materials provided in the research.

\section{Questions of the Research}

The research seeks to answer the following three main questions:

5.1. How to design English for academic writing virtual lab for preservice math and science teachers?

5.2. What is the effect of the virtual English writing lab in developing pre-service math and science teachers' academic writing basic concepts?

5.3. What is the effect of the virtual English writing lab in developing pre-service math and science teachers' academic writing skills? 


\section{Hypotheses of the Research}

The research hypothesized the following alternative hypotheses:

6.1. There would be statistically significant mean differences between participants' mean scores in the pre-post testing of academic writing basic concepts favoring the post testing.

6.2. There would be statistically significant mean differences between participants' mean scores in the pre-post testing of basic academic writing skills favoring the post testing.

\section{7. $\quad$ Research Design}

The research followed the one-group quasi-experimental design with its pre and post testing procedure. Variables of the research included an independent variable (virtual academic writing module) and dependent variables (academic writing basic concepts and academic writing skills). Participants were randomly selected from Hurghada Faculty of Education, Egypt (math and science customized program). Selection of the participants proceeded with the announcement for the course through the online application form of South Valley University Languages Learning and Research Center. Thereafter, the participants were chosen on a voluntarily basis according to specialization (math and science departments) and time of submitting the application. Using the pre and post testing procedure, the mean scores of the participants were compared and statistically analyzed using SPSS program (mean differences measurement using T-test) to verify the difference in the mean scores before and after running the experiment.

\section{Instrumentation}

The research utilized the following instruments designed by the researcher:

1. Basic academic writing skills checklist that aimed at identifying English for academic writing skills needed for the participants. The checklist was validated in terms of validity and reliability. Validity of the checklist was run through content validity (jury validation) and square root of the $r$ value which was 0.80. Using Cronbach Alpha statistic, $r$ value was 0.890 which is a high reliability coefficient.

2. Writing lab framework which aimed at identifying an appropriate frame to design the online writing lab with its objectives, aids, activities, and assessment procedures. It was also validated by a list of jury members who agreed on the suitability of the frame to the objectives of the module.

3. Online Academic Writing Lab module (Available: https://academicwritinglab .zyrosite.com).

4. Basic academic writing skills test that aimed at measuring participants' concepts and academic writing skills (available: 
/forms.gle/jGH9Tjs89HaqkP5R6). The test included a rubric to correct the second part that involved essay writing. In a pre-post testing procedure, the basic academic writing skills test was used. The four instruments were applied in the processes of identifying what skills to develop, how to develop, and identifying the effects of the development.

\section{Participants}

Announcement for the research participation was run through South Valley University Language Learning and Research Center. Students from math and science departments were asked to respond to the online questionnaire in a voluntarily basis. Participants who responded to the questionnaire were 82, while a number of 24 students were excluded from the research for not completing either the whole questionnaire or the reflection sheets at the end of the experiment. The total number of participants who completed all the requirements of the experiment was 58 pre-service math and science students who were grouped into one group and they were asked to respond to the instruments online.

\section{Theoretical Framework}

According to World Bank report (2009), there have been radical changes in Arab world math and science educational programs. The report further recommended that "educational systems need different types of incentive structures and public accountability mechanisms" (P.5). Earlier to this report, with the establishment of official language schools in 1980s, Egyptian educational policies in this important area started to set a vision coined with clear strategies to improve the practices of teaching math and science both at schools and universities' levels. This policy has deeply rooted history that started early in the 70s, 80s, and 90s as well. According to Swain, Monk, and Ghrist (2011), in the year 1977, UNESCO called for a development in science and technology teaching in the Arab States (UNESCO, 1977). They further explained that a 10-year incubation period was implemented later on (1986). This made an early start to a program of educational reform, and this reform continued throughout the tenure from 1986 to 1990. Similarly, ElDeghaidy (2016) stressed that these efforts and developments pursue education in order to attain sustainable development. Hence, the vision to enhance the national practices of math and science teaching emerged and is included in the national Egyptian vision (2020-2030).

Egyptian national vision in math and science teacher education highlighted the development of learning practices as well as meaningful contexts of English language use. For instance, interviews carried out with government advisors and senior ministry officials of secondary and higher 
education suggest that they have two main objectives in mind. The first is to learn new things by observing others, while the second is to learn English as this provides greater access to the global village. This national vision supports the integration of English as a medium of instruction into math and science classes, which includes the use of effective writing as a key language skill in these classes.

In practice, using English as a medium of instruction in teaching math and science courses is challenging due to the means of instruction._For instance, a study by Al Sheikh (2012) stressed the view that both students and teachers agree that using English as a means of instruction is important. However, a major challenge is seen in the difficulty of understanding the content as well as the instruction in English. On a different view, math and science instructors find difficulties in pursuing effective learning among students. Using English as a medium of instruction compared to mother tongue has been a subject of research debate (Gillani et al., 2010; Nordin, 2005; Zuraini, 2014). To sum the argument, students need to master two things: their mother tongue first and then the foreign language to be used as a means of instruction. Al Sheikh also stressed the importance of preparing math and science pre-service teachers with formal trainings on how to effectively use English as a means of instruction.

Using English as a medium of instruction in math and science at the university level is related to actual class practices. The practices followed in math and science pre-service teachers' education shape the strategies and techniques they follow in their classes. For example, Mansor, Mohamed, and Azman (2011) investigated teachers' perspectives of using English as a medium of instruction in teaching mathematics and science. The results and the correlation indicated that environment, methodology, and instruction are significantly associated with students' achievement. However, the teaching methodology indicated a low level of moderate correlation which is believed to be the immediate issue that needed to be addressed in math and science instruction using English. Similarly, Yunus and Ahmed (2017) investigated pre-service teacher's perceptions about using English as a medium of instruction in math and science programs. Results showed that most of the Mathematics and Science trainee teachers hold unfavorable perceptions towards the implementation of the math and science program or policy. Nonetheless, they acknowledge the significant roles of English language. Although using English as a medium of instruction in EFL contexts is important, it is challenging due to its connection with variables such as environment and methodology.

There have been various developments in the instruction of English writing skills that led to the emergence of writing labs use in EFL contexts. History of writing instruction is marked by the shift in viewing writing as a 
process rather than as a product. Therefore, the focus is on how to instruct writing rather than how the product will be. A distinctive development is in the shift to online instruction rather than the face-to-face instruction which was fostered by traditional instruction such as time constraints, home schooling approaches, and the current quarantine issues. Online writing labs were first established in 1993 at Purdue University. According to McGraw (2007), in 2006, Purdue had links to 96 other university OWLs. Within a short time, OWLs have grown rapidly and increased their content. Online writing labs are also virtual solutions to different EFL problems and writing difficulties.

Challenges experienced by students writing in the different EFL contexts in both pre-university and university levels are due to various reasons that are mainly attributed to the type of writing instruction they encounter. More so, writing courses and grading system is different in the university from high school writing (Bartlett, 2003; Hall, 2003; McGraw, 2007). Singh (2019) further investigated academic reading and writing challenges among international EFL Master's students. His findings indicated that the students faced challenges in their academic reading and writing practices such as adhering to academic writing conventions and interpreting text in an English language instructional setting. Challenges in the Egyptian EFL context continue from pre-university settings to university level for distinctive reasons. According to Abdrabo (2020), utilized Cognitive Academic Language Learning (CALA) approach highlights the processes approach in order to overcome various writing difficulties such as "inability to generate ideas related to the topic, provide supporting details, write the proper form of paragraphs and emails, apply correct sentence structure, use different tenses, use good range of vocabulary, and use punctuation and correct word spelling" (p.32). Nevertheless, these pre-university challenges continue to the university level despite the different context.

Although the context of writing instruction at the university level in Egypt is different from school level in terms of scope, instruction, and assessment, there are still various writing challenges in academic writing instruction. Mohamed (2019) expressed the view that "Most EFL students literally practice how to make sentences in English by translating and memorizing English idioms in schools. In college, the core activities in English composition courses include dialogue memorization, grammar, and structured pattern drills." (p. 528). Challenges in academic writing instruction are global educational issues in various university settings not just in the Egyptian context (Bjork, Brauer, Reincker \& Jorgensen, 2003; Brahim, 2016; Hussein, 2013; Tan, 2020). These challenges mainly include the approaches of instruction, resources used, testing procedures, and academic writing drilling techniques. Also, these challenges fostered the need to find new ways 
of instruction, drilling, and assessment for academic writing such as online writing centers or virtual writing labs.

Online writing centers or online writing labs (OWLs) are digital moves from traditional writing classes to online technology-aided classes. Although Harris and Pemberton (1995) assured the challenges of this move towards writing digitization, they asserted that there is great potential. However, planning and shaping of effective user-friendly OWLS takes considerable thought and energy. They further asserted that "attempting only to replicate familiar face-to-face tutorial settings in an electronic text-oriented environment can lead to frustration and defeat as OWL planners find themselves unable to simulate all characteristics of effective tutorials" (p.145). These challenges are no more a core of discussion in a pandemic era where teaching profession moves towards online instruction in a world of academic educational settings including math and science instruction.

In a pandemic pedagogy context, using online writing centers for developing writing is a key solution to effective education. Sheppard (2021) expressed the view that using online writing centers can help educators prepare for "an uncertain" future. Sheppard further contextualized the local challenges within larger scholarly conversations about online writing instruction (OWI) and offered a series of pedagogical and professional best practices that are relevant for future online and hybrid teaching. Similarly, Webb (2021) highlighted the use of online writing labs in teaching and writing during this era of Corona Virus pandemic. In her study, she surveyed 669 online and hybrid first-year writing students based on their perspectives. Results showed that the students most valued their instructor's feedback on their work. This was followed by effective course organization. Students also pointed to peerreview and discussions as important ways they learned with their peers. Hence, using online writing centers with the effective feedback and interactivity can be great tools for developing writing skills.

Writing skills are crucial in pre-service math and science teacher's education programs. Through writing, they can convey ideas and transfer verbal scientific ideas at both class instruction as well as content instruction phases. Academic writing supports their skills in reasoning, description, analysis, prove, and justification. Willis (2011) explained the values of writing instruction to math and science where students can practice writing as a way to integrate math and science concepts without fear. She explained that math and science writing brings more than literacy and communication advantages. The practice of writing can enhance the brain's intake, processing, retaining, and retrieving of information. She further explained that "when writing is embedded throughout the curriculum, it promotes the brain's attentive focus to class work and homework, boosts long-term memory, illuminates patterns, and gives the brain time for reflection" (p.2). Consequently, developing writing skills of math and 
science teachers' writing using English as a medium of instruction is crucial in their pre-service education programs.

\section{Results and Discussion}

The obtained results from this research were generated from both quantitative and qualitative assessment instruments. The quantitative results were obtained from the academic writing test that was carried out in a pre and post testing running, while the qualitative results were obtained from the feedback of the participants from online journals and feedback sheets. The following is a description for the obtained data from the test that were generated through SPSS analysis. This is followed by a discussion of the hypotheses of the research based on the results.

Table 1. Descriptive Statistics of Pre and Post Scores

\begin{tabular}{|c|r|r|r|r|r|}
\hline & $\mathrm{N}$ & Minimum & Maximum & Mean & \multicolumn{1}{c|}{ Std. Deviation } \\
\hline Pre-concept & 58 & 6 & 18 & 11.55 & 2.903 \\
Post-concept & 58 & 10 & 25 & 17.69 & 3.045 \\
Pre-skill & 58 & 2 & 24 & 15.78 & 4.573 \\
Post-skill & 58 & 11 & 29 & 18.97 & 3.579 \\
Pre-total & 58 & 14 & 40 & 27.36 & 6.290 \\
Post-total & 58 & 28 & 45 & 36.38 & 4.137 \\
Valid N (listwise) & 58 & & & & \\
\hline
\end{tabular}

Table 1 indicates the distribution of the participants, their number (58), mean scores, standard deviation, and the type of assessment that was run over two test parts. Firstly, the basic academic writing concepts include models of writing, elements of writing, and stages of writing. Secondly, the basic academic writing skills include prewriting, paragraph writing, editing, and publishing. Table 1 also shows the assessment that was run over the total scores of the participants in the academic writing test, which was used in a pre and post testing procedure. The table shows how the mean scores of the participants were higher in the post testing $(17.59,18.97$ and 36.38) compared to the pre testing $(11.55,15.78$ and 27.36). The differences in the mean scores were analyzed in the following statistical running, which was guided by the hypotheses of the research.

\subsection{First Hypothesis}

H.1. There would be statistically significant mean differences between participants' mean scores in the pre-post testing of academic writing basic concepts favoring the post testing.

To verify this hypothesis, the following statistic was run to compare between the participants' scores in the concepts section at the academic writing test. 
Table 2. Paired Samples Statistics

\begin{tabular}{|c|c|c|c|c|}
\hline & Mean & $\mathrm{N}$ & Std. Deviation & $\begin{array}{l}\text { Std. Error } \\
\text { Mean }\end{array}$ \\
\hline Pair 1 Pre-concepts & 11.55 & 58 & 2.903 & .381 \\
\hline Post-concepts & 17.69 & 58 & 3.045 & .400 \\
\hline
\end{tabular}

Table 2 shows the mean scores of the participants (pre 11.55 compared to post 17.69) in the pre and post testing of the basic academic writing concepts assessment. The following table verifies the significance of differences through the comparison of the mean scores.

Table 3. Paired Samples Test

\begin{tabular}{|c|c|c|c|c|c|c|c|c|}
\hline & \multicolumn{5}{|c|}{ Paired Differences } & \multirow[b]{3}{*}{$t$} & \multirow[b]{3}{*}{$d f$} & \multirow[b]{3}{*}{ Sig. (2.taileco) } \\
\hline & \multirow[b]{2}{*}{ Mean } & \multirow[b]{2}{*}{ Std. Deviation } & \multirow{2}{*}{$\begin{array}{c}\text { Std Error } \\
\text { Mean }\end{array}$} & \multicolumn{2}{|c|}{$\begin{array}{c}95 \% \text { Confidence Interval of the } \\
\text { Difference }\end{array}$} & & & \\
\hline & & & & Lower & Upper & & & \\
\hline $\begin{array}{ll}\text { Pair1 Pre_concept- } & \text { Post_concept } \\
& \text { Pont }\end{array}$ & .6 .138 - & 3.776 & .496 & .7 .131$. & .5 .145 & .12378. & 57 & .000 \\
\hline
\end{tabular}

Table 3 shows that the result accepts the alternative hypothesis and rejects the null hypothesis. There are statistically significant mean differences (sig .000) in the pre and post testing of the basic academic concepts of the participants.

\subsection{Second Hypothesis}

H.2. There would be statistically significant mean differences between participants' mean scores in the pre-post testing of basic academic writing skills favoring the post testing. To verify this hypothesis, the following statistical procedure was run.

Table 4. Paired Samples Statistics

\begin{tabular}{|rr|r|r|r|r|}
\hline & & \multicolumn{1}{|c|}{ Mean } & \multicolumn{1}{|c|}{$\mathrm{N}$} & Std. Deviation & \multicolumn{2}{c|}{ Mean } \\
\hline Pair 1 & Pre-skill & 15.78 & 58 & 4.573 & .600 \\
& Post-skill & 18.97 & 58 & 3.579 & .470 \\
\hline
\end{tabular}

The table shows the differences in the mean scores (pre 15.78 and post 18.97) favoring the post testing. Paired Samples Test gives the hypothesis test results as shown in Table 5. The table also shows the degree of significance. 
Table 5. Paired Sample Test

\begin{tabular}{|c|c|c|c|c|c|c|c|c|}
\hline & \multicolumn{5}{|c|}{ Paired Difterences } & \multirow[b]{3}{*}{1} & \multirow[b]{3}{*}{ df } & \multirow[b]{3}{*}{ Sig. (2taileo } \\
\hline & \multirow[b]{2}{*}{ Nean } & \multirow[b]{2}{*}{ Sto. Deviation } & \multirow{2}{*}{$\begin{array}{l}\text { Stod Error } \\
\text { Nean }\end{array}$} & \multicolumn{2}{|c|}{$\begin{array}{l}\text { 95\% Confidence liternal of the } \\
\text { Ditherence }\end{array}$} & & & \\
\hline & & & & Lower & Upper & & & \\
\hline Pair1 Pre_skill. Post_skill & .3190 & 4.965 & .652 & .4 .495$. & .1 .884 & .4 .893$. & 57 & .000 \\
\hline
\end{tabular}

Table 5 shows that the result accepts the alternative hypothesis and rejects the null hypothesis. Therefore, it can be concluded that there are statistically significant mean differences between the participants' scores in the pre and post testing of basic academic writing skills favoring the post testing.

To compare between the mean scores of the participants in the total academic writing test sores, the following statistic was run.

Table 6. Paired Samples Statistics

\begin{tabular}{|cc|r|r|r|c|}
\hline & & \multicolumn{1}{|c|}{ Mean } & \multicolumn{1}{c|}{$\mathrm{N}$} & Std. Deviation & Std. Error Mean \\
\hline Pair & Pre-total & 27.36 & 58 & 6.290 & .826 \\
1 & Post-total & 36.38 & 58 & 4.137 & .543 \\
\hline
\end{tabular}

Table 6 shows the difference in the mean scores of the participants in the pre testing (27.36), the post testing (36.38), and their standard deviation (pre 6.290 and post 4.137). The table also shows that the standard deviation of the participants in the pre testing is higher than the post testing standard deviation. This illustrates that the development that happened in the scores is almost homogenous in the different sections of the test.

Table 7. Paired Samples Correlations

\begin{tabular}{|cc|c|c|c|}
\hline & $\mathrm{N}$ & Correlation & Sig. \\
\hline $\begin{array}{c}\text { Pair } \\
1\end{array} \begin{array}{c}\text { Pre-total score \& Post- } \\
\text { total score }\end{array}$ & 58 & .498 & .002 \\
\hline
\end{tabular}

Table 7 shows the correlation between the pre and post testing of the total scores of the participants. Although this correlation is moderate, it is significant. The following table shows the difference in the mean score of the participants. 
Table 8. Paired Sample Test

\begin{tabular}{|c|c|c|c|c|c|c|c|c|}
\hline & \multicolumn{5}{|c|}{ Paired Diterences } & \multirow[b]{3}{*}{1} & \multirow[b]{3}{*}{ dif } & \multirow[b]{3}{*}{ Sig.(2.tallede) } \\
\hline & \multirow[b]{2}{*}{ Nean } & \multirow[b]{2}{*}{ Sto. Deviation } & \multirow{2}{*}{$\begin{array}{l}\text { Stol Error } \\
\text { Nean }\end{array}$} & \multicolumn{2}{|c|}{$\begin{array}{l}\text { 958 Confidence intenal of the } \\
\text { Diterence }\end{array}$} & & & \\
\hline & & & & Lower & Upper & & & \\
\hline Pair 1 Pre__total P Post_tiotal & .9017. & 5.996 & .787 & .10 .594 & $.7,44$. & .11 .454 & 57 & .000 \\
\hline
\end{tabular}

Table 8 shows that there are statistically significant mean differences between the participants' scores in the pre and post testing of the academic writing test total score. This result accepts the alternative hypothesis and rejects the null hypothesis. Thus, the quantitative results show that the online writing lab could develop the participants' basic academic writing concepts and skills.

Another qualitative analysis was run through the journal. Results obtained from the reflection journal showed the following: (a) students assured their satisfaction with materials and tasks in the program; (b) students also reported the value of the online lab in discussing their writing; and (c) they showed the satisfaction with the feedback it provided to their writing. The feedback that the participants provided about the lab activities and instruction was a helpful input to adapt the pace of instruction and the grading of their writing. Participants could also discuss their scores based on the rubric that was used for correction. For example, Nada stated that "this is my first time I have my opinion in my own writing...I think now I know my writing mistakes well and I have the plans to correct them". The reflection sheet was used in three stages during the research. The first was before the use of the lab, the second was during the instruction and lab use, and the third was after completion of the course and the test. Comments of the participants varied according to the type of challenges they faced, instruction stage, and the feedback provided to them.

Therefore, based on both the qualitative and quantitative results, this integration of virtual academic English Writing Lab setting in pre-service math and science teacher education could develop the participants' academic writing concepts and skills.

\section{Discussion}

Using the one-group quasi experimental design and following both quantitative and qualitative data interpretation, the key result of the research was the effectiveness of using online writing lab in developing participants' academic writing concepts and skills. This result highlights the use of online 
writing labs which agrees with other similar studies (Sheppard, 2021; Webb, 2021; Ahmad, 2020; Tan, 2020).

Results also assured that the online writing labs enhanced participants' writing skills and their concepts about academic writing. Furthermore, OWLs also support individualization of learning and autonomy. MacGraw (2007) also stated that "OWLs can function to help students write better. An OWL can act as a tutor through the use of static instructional reference materials (e.g., electronic handouts) and can also be a means to explore materials on how to write better" (p. 21). These claims were supported by both the quantitative and qualitative results of the research.

Results confirm that math and science students' viewed OWL as an assessment tool for learning. This result was supported by the findings of Alquraan and Al-Shaqsi (2019) and also Kaptan and Kiray (2011). Similarly, Utley and Moseley (2006) expressed the view that self-efficacy is a key requirement in math and science teacher education which can be achieved through content-based materials. This learning environment agrees with the content-based materials provided in the labs.

Challenges of integrating the online writing lab as obtained from the qualitative results include either technical or academic challenges. For instance, since there is no freeware for writing labs, participants had to complete the second part of the test using pen and paper. Also, in some sessions, participants showed complaints about using online editing tools and blogging templates. The obtained results further highlighted the value of OWL setting in math and science teacher English course instruction.

\section{Recommendations of the Research}

In the light of the obtained data, the research recommends identifying the effect of specialization on academic writing performance. Research should also identify the relation between Content and Language Integrated Learning (CLIL) approach to the courses of math and science pre-service teachers. Another recommendation is to identify the relation between pre and in service math and science teacher professional development courses, materials, and online courses.

\section{Conclusion and Implications}

The research recommends integrating virtual English writing lab setting in pre-service math and science teachers' educational programs and courses such as English. This integration can develop pre-service teacher's writing skills, key concepts, and academic skills in writing. Course designers can also make use of OWLs in providing online tracks and materials to develop similar participants at both pre and in-service levels. In assessment level, the results highlight the use of online assessment for learning and not of 
learning. This paves the way for further practical modules and courses in online assessment using English writing labs. Thus, teachers can find practice ideas for the different stages of writing instruction at university level. Students can also make use of the various windows offered by the virtual labs to practice, develop, and assess their writing skills in their fields of specialization.

\section{References:}

1. Abbadi, H. (2013). The effect of cohesive devices on EFL students' academic writings, MA Thesis, Faculty of Arts, Omdurman University, Sudan.

2. Ahmad, S. (2020). Virtual research teams to develop EFL student' research and academic writing skills. Faculty of Education Journal, Menoufya University, Vol (2), No (1).

3. Al Hussein, A. (2018). The problems encounter university students in using reflexive pronouns as reference in academic writing: A case of EFL students of Omdurman, MA Thesis, Faculty of Arts, Omdurman University, Sudan.

4. Alquraan, M. \& Al-Shaqsi, A. (2019). Math and Science Post-basic Education School Teachers' Use of Assessment for Learning and Assessment of Learning Practices in Oman. Journal of Educational and Psychological Studies. DOI. http://dx.doi.org/ 10.24200/jeps.vol12iss4pp615-627.

5. Al Sheikh, A. (2012). Egyptian Science / Math teachers' and students' attitudes towards employing English as a medium of instruction. Journal of Mansoura Faculty of Education, Vol (87), N. (2).

6. Adam, T. \& Tatnall, A. (2010). Use of ICT to Assist Students with Learning Difficulties: An Actor-Network Analysis. In Key Competencies in the Knowledge Society (pp. 1-11). Berlin, Heidelberg: Springer. DOI: 10.1007/978-3-642-15378-5_1.

7. Alqiawi, D. (2015). A proposed model on developing students' academic writing based on critical thinking. International Interdisciplinary Journal of Education, vol (4), No (12)

8. Abdrabo, A. (2020). Developing EFL preparatory school pupils' process writing through the cognitive academic language learning approach (CALLA). Journal of Faculty of Education, 121 (5), Benha University, Egypt.

9. Ali, A., Qoura, A., \& Al Sheikh, A. (2018). An online training program based on international electronic medical journals criteria to develop physicians' academic English writing skills. Journal of Research in Curriculum, Instruction and Educational Technology, Vol (4), No (2). 
10. Bartlett, T. (2003). Why Johnny can't write even though he went to Princeton. Chronicle of Higher Education,49(17).

11. Bjork, L., Brauer, G., Rienecker, L., \& Jorgensesn, P. (2003). Teaching Academic Writing in European Higher Education.Kluwer Academic Publishers, New York.

12. Brahim, H. (2016). Investigating problems in learning academic writing case of first year master students of English at KasdiMerbah University Ouargla. Master Thesis, KasdiMerbah University Ouargla, Algeria.

13. CEFR

Global

Scale.

Retrieved: https://www.coe.int/en/web/common-european-framework-referencelanguages/table-1-cefr-3.3-common-reference-levels-global-scale.

14. El-Deghaidy, H. (2016). Science education in Egypt based on integrating ecological needs and STEAM education. Conference paper, Retrieved: https://www.researchgate. net/publication/ 281592230.

15. Ewiss, M. (2020). Empowering the Egyptian's education in the era of COVID-19. Journal of Research in Humanities and Social Science, Vol( 8), No. (11), pp: 43-56.

16. Hall, H. (2003). Why students can't write. Community College Week, 16(9), pp.4-5.

17. Harris, M. \& Pemberton, M. (1995). Online Writing Labs (PWLs): Taxonomy of options and issues. Journal of Computers and Composition, 12, pp. 145-159.

18. Hussein, A. (2013). The effect of cohesive devices on EFL students' academic writings. Master Thesis, Um Dorman University, Sudan.

19. Hyland, K. (2007). Genre pedagogy: Language, literacy and L2 writing instruction. Journal of Second Language Writing, 16, 148-164.

20. Hussein, A. \& El Mahallawi, N. (2018). The Effectiveness of a Website Based on Brain -Based Learning Theory in Developing Academic Writing Skills and Self -Regulated Learning Strategies Among Special Diploma Students at the Faculty of Education Alexandria University. Journal of Arabic Studies in Education and Psychology, Vol (96), No (4).

21. Gillani, I.G., Khourshid, K., Jumani, N., \& Rahman, F. (2010). A comparison of student's achievement in the subject of English: a Pakistani context in India strength for today and bright hope for tomorrow, Vol (10), N. (8). Retrieved: www./http.englishachievementpa/aug 2010/com.

22. Kaptan, F. \& Kiray, M. (2011). The effectiveness on an integrated science and mathematics program: science centered mathematics- 
assisted integration. Journal of energy education, science and technology, vol (4) No. (2), pp. 943-965.

23. MacGraw, W. (2007). Students and online writing labs (OWLS): Challenges, learning strategies and attributes of high quality OWLS. PhD Dissertation, University of Wisconsin-Madison

24. Mackiewicz, J. \& Thompson, I. (2018). Spoken written language in writing center talk. Journal of Linguistics and Education, 47, pp. 4758. Retrieved: https://doi.org/10.1016/j .linged.2018.07.003.

25. Mansor, N., Mohamed, B., \& Azman, M. (2011). Teachers' perspectives of using English as a medium of instruction in mathematics and science subjects. International Journal of Instruction, Vol. (4), N. (2).

26. Mohamed, D. (2019). Using a weblog-oriented program for promoting English majors' academic writing and authorial identity, Journal of Research in Education and Psychology, Minia Faculty of Education, Minia University.

27. Nordin, A. (2005). Students' perception on teaching and learning math in English. . Journal of Matematik dan Sains Pendidikan, 14 (1).

28. Sheppard, J. (2021). Pandemic Pedagogy: What We Learned from the Sudden Transition to Online Teaching and How It Can Help Us Prepare to Teach Writing in an Uncertain Future. Composition Studies, Vol. 49, Issue 1, pp. 60-83.

29. Singh, M. (2019). Academic reading and writing Challenges among international EFL Master's students in a Malaysian university: The voice of lecture. Journal of International Students.Vol. 9, No. 4, pp. 972-992.

30. Summers, J. (2019). Guidelines for conducting research and publishing in marketing: From conceptualization through the review process. In Stewart, D. \& Ladik, D. (Eds.), How to get published in the best marketing journals. Cheltenham, UK: Edward Elgar.

31. Swain, J., Monk, M., \& Ghrist, M. (2011). The overseas in-service Egyptian teacher education program: distal and proximal reflections on policy and change. Journal of in-service education, 29:1, pp.61-80.

32. Tan, B. (2020). Innovating Writing Centers and Online Writing Labs outside North America. Asian EFL Journal, Volume 13, Issue 2, pp. 391-418.

33. University of Leeds (2019). Academic Writing: What is academic writing?

Retrieved: https://library.leeds.ac.uk/info/14011/writing/106/academic_writing.

34. Utley, J. \& Moseley, C. (2006). The effect of an integrated science and mathematics content-based course on science and mathematics 
teaching efficacy of pre-service elementary teachers. Journal of Elementary Science Education, Vol. 18, No. 2.

35. Webb, N. (2021). Teaching writing online amid a pandemic. Perspectives College of Humanities. Retrieved: https://humanities.utah.edu/perspectives/2020/teaching-writingonline-amid-pandemic.php.

36. Willis, J. (2011). The Brain-Based Benefits of Writing for Math and Science Learning: Brain based learning. Retrieved: https://www.edutopia.org/blog/writing-executive-function-brainresearch-judy-willis.

37. World Bank (2009). Education in the Arab world: shift to quality in math, science and technology teaching. Report No 2, 4.

38. Yang, R. \& Allison, D. (2004). Research articles in applied linguistics: Structures from a functional perspective. English for Specific Purposes, 23 (3), 264-279.

39. Yunus, M. \& Ahmad, S. (2017). The use of English in teaching mathematics and science: The PPSMI policy vis-à-vis the DLP. Journal of Advances in language and literacy studies, Vol. (8), N. (1).

40. Zuraini, R. (2014). Teaching and Learning Mathematics and Science in a Second or Third Language. PhD Dissertation, Deakin University, Malaysia. 